\title{
Repeat breeding syndrome in crossbred dairy cows of Bangladesh: some important characteristics and influential factors
}

\author{
S. Padder, R. K. Barson, M. M. Rahman, M. M. U. Bhuiyan, J. Bhattacharjee* \\ Department of Surgery and Obstetrics, Faculty of Veterinary Science, Bangladesh Agricultural \\ University, Mymensingh-2202, Bangladesh
}

\begin{abstract}
\section{Background}

Repeat breeding syndrome (RBS), an important reproductive disorder of dairy cattle, results in high economic losses in the dairy industry. The study was conducted to determine the factors of repeat breeding in crossbred dairy cows at selected areas of Bangladesh.
\end{abstract}

\section{Methods}

A total of 592 breedable cows from 34 farms were examined from Mymensingh and Chittagong district. Seventy cows were identified as repeat breeder cows and another 23 cows were randomly selected as healthy control cows for the study.

\section{Results}

The number of calving, the interval between first post-partum heat and last service date, number of services failed and consecutive services failed, the number of medications given, and number of suckling were found significantly higher in repeat breeder cows compared to normal healthy cows. Body weight and Body condition score (BCS) were significantly lower in repeat breeder cows compared to normal healthy cows. There were no significant differences in the estrus cycle length and concentrate feeding in both repeat breeder and healthy cows. The lowest occurrence of repeat breeder was recorded in cows fed with a larger amount of green grass. Remarkably, the highest occurrence of repeat breeder was recorded in cows fed with a significant amount of straw.

\section{Conclusion}

The identified features of repeat breeding syndrome will help in disseminating awareness on factors affecting the occurrence of repeat breeding syndrome in crossbred cows.

Key words: Repeat breeder cows, crossbred, characteristics, Bangladesh

*Correspondence: bhattacharjee@bau.edu.bd

Copyright (C 2018 Bangladesh Society for Veterinary Medicine. This is an open access article under the CC BY license (http://creativecommons.org/licenses/by/4.0/), which permits unrestricted use, distribution, and reproduction in any medium, provided the original author and source are credited. 


\section{Introduction}

In Bangladesh, many peoples live in rural areas with agriculture and dairying as their main component of livelihood. Dairy farming plays a vital role in the rural economy of Bangladesh. Dairy could be considered as an important sector for rural development and poverty alleviation. Poor conception rate, prolonged inter-calving interval, and repeat breeding syndrome have been identified as major constraints of profitable dairy farming in Bangladesh (Alam and Gosh, 1988; Shamsuddin et al., 2001). A repeat breeder is generally defined as any cow that has not conceived after three or more consecutive services, has a normal estrous cycle, is free from palpable abnormalities, shows no abnormal vaginal discharges, has calved at least once before and is less than ten years old (Zemjanis, 1980). As repeat breeding is a multifactorial disease, many risk factors such as the breed of cows, herd size, body condition score, age, and parity may influence the occurrence of repeat breeding in cows. Other factors such as milk production, lactation length, inter-calving interval, suckling, and managerial factors may affect the occurrence of repeat breeding in cows. Incorrect time of insemination is one of the leading causes of repeat breeding syndrome in Bangladesh (Shamsuddin et al., 2001).

Prevalence and risk factors of repeat breeding cows in dairy farms in urban areas have been investigated in Bangladesh (Asaduzzaman et al., 2016). Limited studies have been conducted on determining management-based risk factors of repeat breeding among crossbred dairy cows. Therefore, it is important to know the management and cow-related factors that may raise the repeat breeding syndrome. The objectives of the present study were to determine the risk factors for the occurrence of repeat breeding syndrome in crossbred dairy cows and the management faults that might be responsible for repeat breeding syndrome of crossbred dairy cows of Bangladesh.

\section{Materials and Methods}

\section{Study areas}

A total of 34 Commercial dairy farms having 592 crossbred dairy cows were randomly selected in different villages of Phulpur and Patiya Upazilla under Mymensingh and Chittagong district where Community-based Dairy Veterinary Foundation (CDVF), Bangladesh Agricultural University, Mymensingh has been providing productivity veterinary services to the farms.

\section{Identification of repeat breeding cows}

The cows with the complaint of repeated conception failure were identified in the farms and the owners were interviewed for the history of the problem and the cows were examined clinically for diagnosis of repeat breeding syndrome. A total of 70 repeat breeding cows were diagnosed and treated during the study period.

\section{Questionnaire formation and data collection}

A questionnaire was prepared according to the objectives of the investigation and was designed in a simple way so that the farmers could understand easily. The questionnaire included information of age, breed, body condition score (BCS), feeding practices, reproductive diseases, other diseases, age at puberty (month), parity, last calving date, service needed for previous pregnancy, date of first service after last parturition, date of last service, type of service, pregnancy period (month), service needed for the latest conception, number of service given, problem at last pregnancy, problem at parturition, suckling and milk yield.

\section{Determination of breed, age and parity of cows} The breed of cows was determined by observing the phenotypic characteristics of the breed as well as by observing farm register if any. The age of cows was determined from the register book or by interviewing the owner and/or by observing dentition where necessary. The parity of cows was also determined by interviewing the farmer and by noting from farm register if any. 
Observation of milking yield, feeding and management of cows

Milk yield, feeding and management practice of the farms were recorded from the direct interviewing of the dairy farmers and/or farm registry, if any. Most cattle were fed with paddy straw and green grass collected from various places. Approximately 8-10 kilograms of roughages were given to each animal daily. Some cattle were grazed every day for several hours in the open field. Some farmers also supplied concentrate feed to their cows daily. The concentrates were mainly rice polish, wheat bran, oil cake and common salt. All cattle had free access to drinking water. Conditions of floors were observed by visual inspection to check whether the floor was made of concrete or brick. Hygienic conditions like dry, wet, dry and soiled with dung, wet and soiled with dung etc. were checked and recorded properly. The ventilation system was noticed, as it is an important aspect of farm management. Some farms had natural ventilation system. Whereas, some other farms have Air inlet or Fan system.

\section{Determination of body condition score}

The BCS was evaluated by visual examination of fat deposition in the cows and scored from 1 to 5 scales by following (Bewley and Schutz, 2008).
The BCS ranged from 2 to 3.5. A score of 1 was extremely thin and a score of 5 was extremely fat.

\section{Determination of estrus and pregnancy}

The farmers detected the estrus of cows on the basis of the clinical manifestation of estrus signs and thereafter inseminated the cow by a trained AI technician using frozen semen. The interval between the onset of estrus and insemination was determined by interviewing either the AI technicians or farmers or by examining the register if any.

\section{Statistical analysis}

The data obtained from the questionnaire was entered into the Microsoft Excel spread sheet and analyzed by Graph Pad Prism Statistical Software. The difference between the groups was considered significant when the $\mathrm{P}$ value was less than 0.05 .

\section{Results and Discussion}

The associated risk factors influencing repeat breeding were examined in a total of 34 dairy farms having 592 crossbreed dairy cows and the results are summarized in Table 1. Seventy cows were found as repeat breeder and 23 cows were selected as healthy (control cows).

Table 1. The comparison of different factors in repeat breeding syndrome between affected and healthy cows

\begin{tabular}{lll}
\hline \multicolumn{1}{c}{ Factors } & $\begin{array}{l}\text { Repeat breeding cows } \\
(\mathrm{n}=70) \text { (Mean } \pm \text { SEM })\end{array}$ & $\begin{array}{l}\text { Control cows } \\
\text { (Healthy cows) } \\
(\mathrm{n}=23)(\mathrm{Mean} \pm \text { SEM) }\end{array}$ \\
\hline Parity & $2.84 \pm 0.15^{* *}$ & $2.04 \pm 0.25$ \\
Body weight (Kgs) & $357.1 \pm 9.91^{*}$ & $394.8 \pm 18.63$ \\
The interval between first post-partum heat and last service (Days) & $232 \pm 19.68^{* * *}$ & $15.13 \pm 3.59$ \\
Number of missed service & $11.05 \pm 0.94^{* * *}$ & $0.71 \pm 0.17$ \\
Number of consecutive services missed & $5.09 \pm 0.25^{* * *}$ & $0.87 \pm 0.19$ \\
Number of estrus cycle length (Days) & $22.13 \pm 0.55$ & $21.17 \pm 0.19$ \\
Number of medications given & $0.56 \pm 0.06$ & $0.26 \pm 0.09$ \\
Number of suckling & $1.47 \pm 0.08^{*}$ & $1.22 \pm 0.09$ \\
Body condition score (1-5 Scale) & $2.46 \pm 0.07^{* * *}$ & $2.89 \pm 0.08$ \\
Amount of straw given (Kgs) & $3.09 \pm 0.48^{* * *}$ & $0.22 \pm 0.12$ \\
Amount of concentrate given (Kgs) & $8.07 \pm 0.38$ & $8.04 \pm 0.32$ \\
Amount of broken rice given (Kgs) & $0.09 \pm 0.04$ & $0 \pm 0$ \\
Amount of green grass given (Kgs) & $29.81 \pm 1.13^{*}$ & $33.52 \pm 0.87$ \\
\hline
\end{tabular}

Asterisks indicate the significant differences between the columns. *Indicates p value is 0.01 to 0.05 ; **Indicates $\mathrm{p}$ value is 0.001 to $0.01 ; * * *$ Indicates $\mathrm{p}$ value is 0.0001 to 0.001 
Effect of parity on the occurrence of repeat breeding syndrome

The present investigation clearly demonstrates that the number of parity (calving) was significantly higher $(\mathrm{P}=0.0086)$ in repeat breeder cows compared to normal healthy cows (Table 1; Figure 1). In fact, Bonneville-Hébert et al (2011) also found a significantly higher number of repeat breeder cows in parity 2 and beyond. This fact may be explained as a cow gets older and parity increases, the uterine tissue becomes senile and the organ becomes more prone to infections.

Effect of body weight on the occurrence of repeat breeding syndrome

Effects of body weight were shown significantly lower $(\mathrm{P}=0.0430)$ in repeat breeder cows compared to healthy cows (Table 1). In the present study, body weight was significantly lower in repeat breeder cows compared to normal healthy cows. Lower body weight is the indication of poor nutrition. Nutritional deficiency like the micro-minerals deficit in cervicovaginal mucus could be the cause of conception failure in repeat breeding cows (Gohel et al., 2012) reported in the previous study. Lower bodyweight cow suffers from negative energy balance that results in mobilization of body fat and loss of body condition score, reduced serum progesterone concentrations and pregnancy rate (Butler, 2005).

Effect of interval between first post-partum heat and last service date on the occurrence of repeat breeding syndrome

The interval between first post-partum heat and last service date was significantly higher $(\mathrm{P}<0.0001)$ in repeat breeder cows compared to healthy cows (Table 1). The repeat breeder and healthy cow had estrous cycle lengths of normal duration. However, in our study as compared with normal, repeat breeder displayed a significantly longer interval from onset of estrus to ovulation. Our findings were also in agreement with the studies of Pérez-Marín \& España (2007) which says that the interval between first post- partum date and last service date was significantly higher in repeat breeder cows compared to normal healthy cows, according to this study.

Effect of the number of services failed (both consecutive services and the total number of services) and length of estrus cycles on the occurrence of repeat breeder syndrome

The number of services failed was significantly higher $(\mathrm{P}<0.0001)$ in repeat breeder cows compared to healthy cows. The number of consecutive services failed was significantly higher $(\mathrm{P}<0.0001)$ in repeat breeder cows compared to healthy cows. In case of estrous cycle length, there were no significant differences in the estrous cycle length in repeat breeder cows and healthy cows. According to the present study, the number of missed service was significantly higher in repeat breeder cows compared to normal healthy cows. Also, the number of consecutive services missed was found significantly higher in repeat breeder cows compared to normal healthy cows. This could be explained as due to poor heat detection and lack of skilled AI technician in artificial insemination, there might be some missed serviced as well as consecutive missed service. The poor heat detection is one of the main causes of RBS and infertility in cattle (Pérez-Marín \& España, 2007). The Previous study said errors in heat detection have a substantial effect on the length of the breeding period, conception rates, day's open and calving interval (Muxlow, 2005). The previous study of Muxlow (2005) also reported that some people related factors including knowledge of heat signs, heat checks per day, time of observations, responsibility for observation and reporting of observations are responsible for poor heat detection.

The most reliable behavior symbolizing estrus is when the cow stands to be mounted by other animals. However, higher producing cows have been reported to exhibit a shorter duration of estrus than lower producing cows (Lopez et al., 
2004). According to the present study, there were no significant differences in the estrous cycle length in repeat breeder cows and normal healthy cows.

Effect of medication given on the occurrence of repeat breeding syndrome

In the present study, repeat breeder cows received significantly higher $(\mathrm{P}=0.0109)$ number of medications compared to normal healthy cows. This is may be due to farmers were trying to improve the fertility of their animals by different measures. As the improvement in conception rate after correct medications is the normal phenomena that were also reported by Lin et al. (2002). Lin et al (2002) reported the positive effect of aquapuncture therapy. i.e. acupuncture combined with injections. Likewise, Khair (2005) also obtained a higher recovery rate of repeat breeding cows after treatment with penicillin than that of their controls.

Effect of suckling on the occurrence of repeat breeding syndrome (RBS)

Effects of the number of suckling were significantly lower in healthy cows compared to repeat breeder. The number of suckling was significantly $(\mathrm{P}=0.0349)$ higher in repeat breeder cows compared to healthy cows. In the present investigation, the number of suckling was significantly higher in repeat breeder cows compared to normal healthy cows. Shamsuddin $e t$ al. (2001) and Siddiqui et al (2013) discussed the factors affecting first services conception rate and reported higher first service conception rate in cows with once or twice suckled than that of several times daily. The reason for the negative effect of suckling on conception rate may be explained by the fact that suckling inhibits the tonic GnRH and LH secretion in cows.

Effect of body condition score on the occurrence of RBS

Effects of body condition score (BCS) are considered as one of the most influential factors in the occurrence of repeat breeding syndrome. BCS was significantly lower $(\mathrm{P}=0.0001)$ in repeat breeder cows compared to normal healthy cows. Lower BCS cows suffer more from negative energy balance resulting in increased occurrence of repeat breeding. Similar to the present study, poor body condition caused low conception rate in cows of Bangladesh (Shamsuddin et al., 2001).

\section{Effects of feeding practices on the occurrence of RBS}

The highest occurrence of RBS was recorded in cows fed with straw in a greater amount than that of healthy cows fed with straw in a lesser amount. Repeat breeder cows were given significantly greater $(\mathrm{P}<0.0001)$ amount of straw compared to normal healthy cows. Both repeat breeder and healthy cows were given a similar amount of concentrate. But the significant difference was not observed while feeding a similar amount of concentrate in both repeat breeder and healthy cows. Both repeat breeder and healthy cows were given broken rice. However, healthy cows were not feed broken rice at all. Only repeat breeder cows have a significant effect on broken rice feeding. The lowest occurrence of RBS was recorded in cows fed with green grass in a greater amount than that of cows fed with green grass in a lesser amount. Repeat breeder cows were given significantly lower $(\mathrm{P}=0.0112)$ amount of green grass compared to healthy cows. In the present study, feeding practices affected the occurrence of repeat breeding in crossbred cows. The higher occurrence was observed in cows received straw and broken rice than that of green grass and concentrate. Nutrition has long been known to have a profound influence on the reproductive performance of female cattle (Butler, 2005; Shamsuddin et al., 2001). Moreover, prolonged deficiency of energy and protein in the diet can exert chronic stress on the hypothalamicpituitary-ovarian axis, which will have negative effects on conception rate (Siddiqui et al., 2002). According to this study, it can be suggested that the farmers should provide better feeding through supplementation of concentrate and green grass. However, further experiments required to explaining this factor more accurately. 
Effect of herd size on the occurrence of RBS We found a positive correlation between the occurrences of repeat breeding syndrome and herd size (Spearman $\mathrm{r}=0.4580 ; \mathrm{p}=0.0096$ ) (Figure 2). According to our study repeat breeder cows were found higher in number at larger herd. This can be explained according to previous study of Hewett (1968), which reported that, cows received more individual attention from the owner in smaller farms that is quite similar to our study. Estrus detection efficiency is high in small size farm compared to large farm size.

\section{Effect of diseases or accident in the last calving on the occurrence of RBS}

There was a positive association between RBS and calving difficulties. Dystocia was also the most significant risk factor directly associated with RBS (Lafi and Kaneene, 1992). Problems during parturition like metritis, retained placenta etc. lead to conception failure. Previous study stated that retained placenta increases the risk of developing metritis (Laven and Peters, 1996). The present findings are also with the agreement that most of the cases of retained placenta were followed by metritis complex and ultimately lead to conception failure. Another study found that $25 \%$ to $50 \%$ of retained placentas were associated with metritis (LeBlanc, 2008). Similarly, according to present study, cows having difficulties at last calving found susceptible to repeat breeding than that having no difficulties at last calving. (Figure 3)

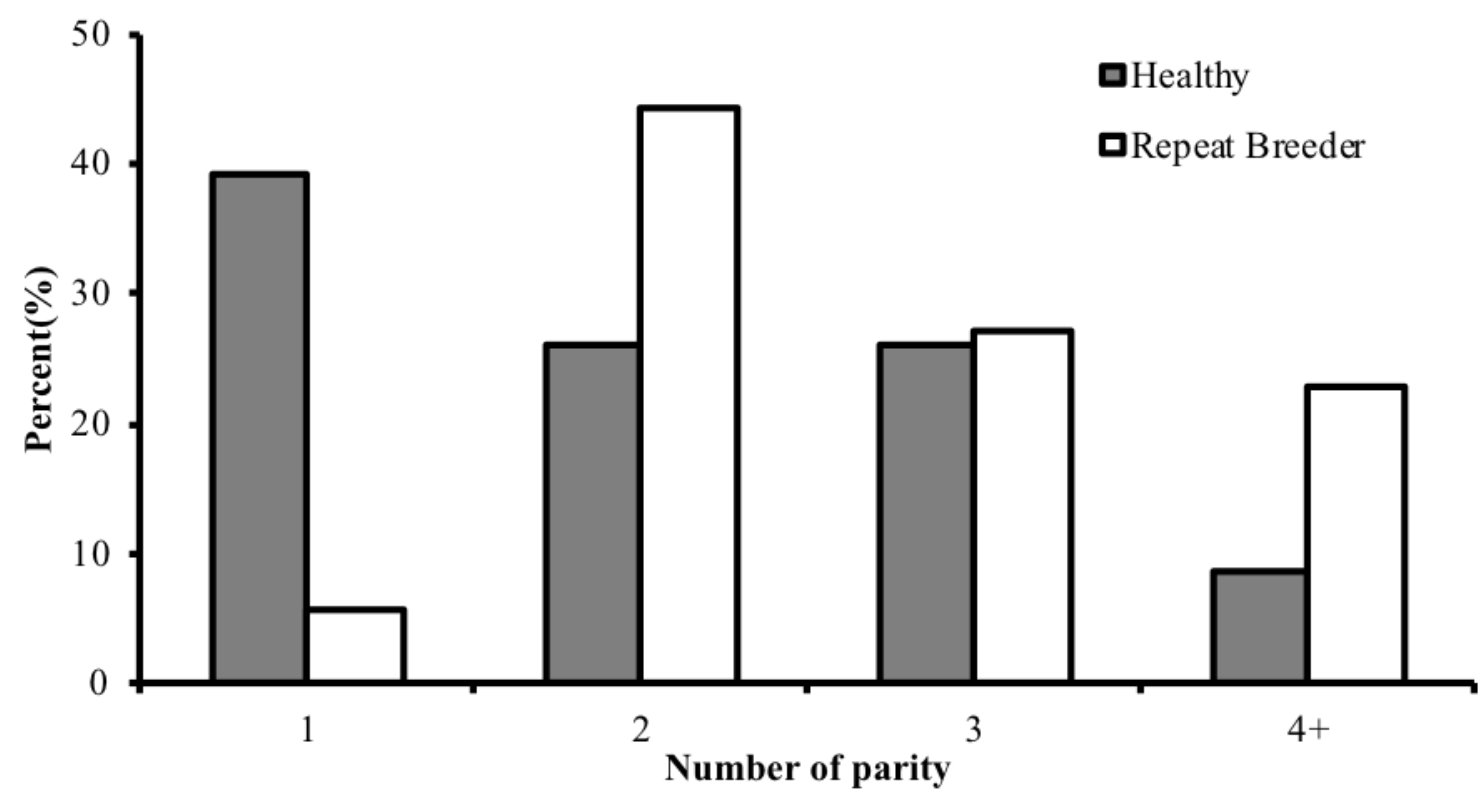

Figure 1. Total percentage of healthy and RBS affected animals of the study in different pariety group 
Repeat breeding syndrome in crossbred dairy cows

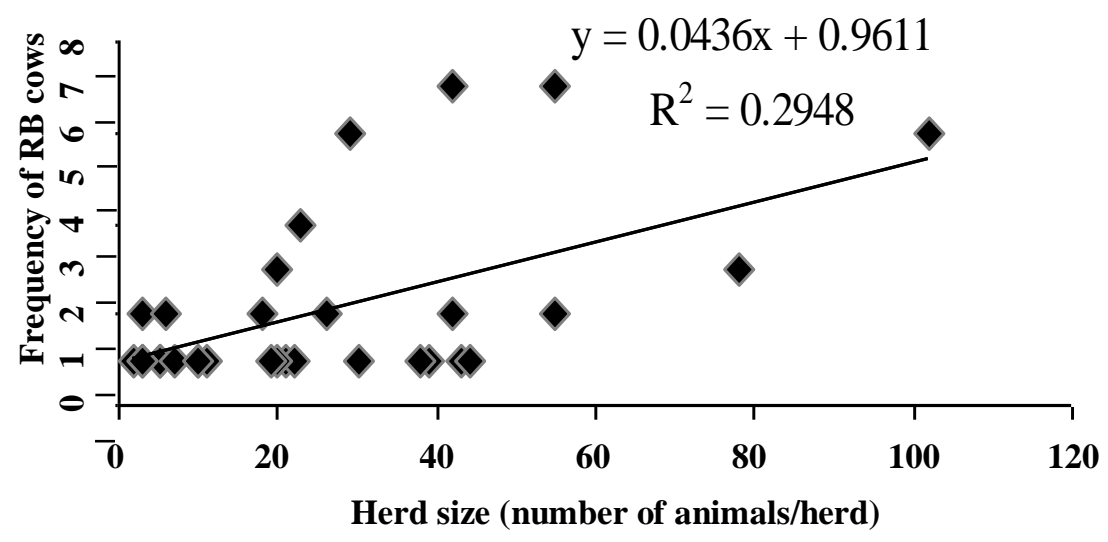

Figure 2. Frequency of repeat breeding syndrome in relation to herd size.

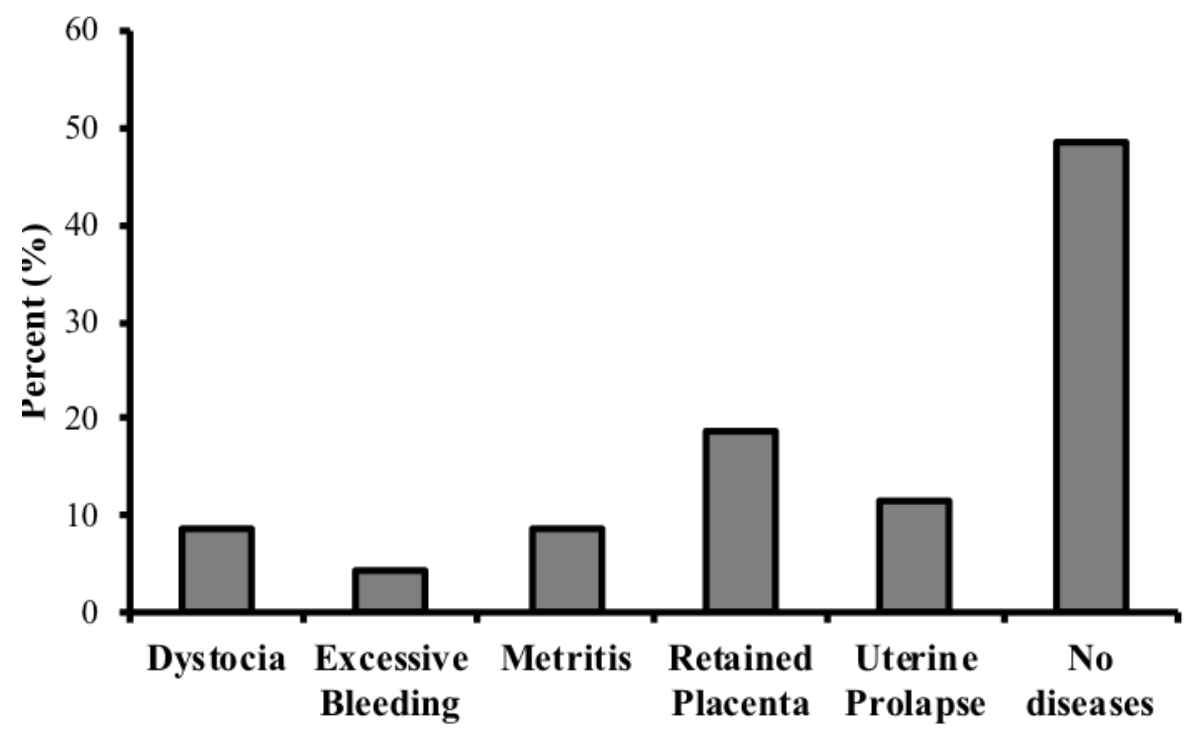

Figure 3. Percentage of occurrence of any other diseases in previous calving in RBS affected cows

\section{Conclusions}

In conclusion, it can be said that the number of calving, body weight, the interval between first post-partum heat and last service, number of services missed and number of consecutive services missed increases in repeat breeder crossbred cows. However, farmers and veterinarian need to be aware of proper medications for those cows. It is very important for the farmers and dairy practitioners to take care of the number of suckling and body condition score of the cow by giving proper feeding regime including straw, concentrate, broken rice and green grass. Because green grass and concentrate were found greatly influencing the onset of repeat breeding syndrome.

\section{Funding}

This work was supported by the grants for advanced research in science from the Ministry of 
Education, Government of the People's Republic of Bangladesh (LS1403) to Principal Investigator Dr. Jayonta Bhattacharjee.

\section{References}

1. Alam MGS and Gosh A. Reproductive performance in cows: it's relation to parity and season. Bangladesh Veterinary Journal. 1988; 22:51-61.

2. Asaduzzaman KM, Bhuiyan MMU, Rahman MM and Bhattacharjee J. Prevalence of repeat breeding and its effective treatment in cows at selected areas of Bangladesh. Bangladesh Journal of Veterinary Medicine. 2016; 14 (2): 183-190.

3. Bewley JM and Schutz MM. An Interdisciplinary Review of Body Condition Scoring for Dairy Cattle. The Professional Animal Scientist. 2008; 24 (6): 507-529.

4. Bonneville HA, Bouchard E, Tremblay DD and Lefebvre R. Effect of reproductive disorders and parity on repeat breeder status and culling of dairy cows in Quebec. The Canadian Journal of Veterinary Research. 2011; 75 (2): 147-151.

5. Butler WR. Nutritional interactions with reproductive performance in dairy cattle. Animal Reproduction Science. 2005; 6061:449-457.

6. Gohel MM, Kavani FS and Hadiya KK. Effect of body condition score and fertility status on proteins and micro-minerals profile of estrual mucus in Gir cows. Indian Journal of Animal Reproduction. 2012; 33:61-63.

7. Hewett CD. A survey of the incidence of the repeat breeder cows in Sweden with reference to herd size, season, age and milk yield. British Veterinary Journal. 1968; 124 (8):342-352.

8. Khair A. Hormonal intervention to increase the fertility in anoestrus and repeat breeding cows. MS in Theriogenology. Thesis. Department of Surgery and Obstetrics, Faculty of Veterinary Science, Bangladesh Agricultural University, Mymensingh; 2005.
9. Lafi SQ and Kaneene JB. Epidemiological and economic study of the repeat breeder syndrome in Michigan dairy cattle. I. Epidemiological modeling. Preventive Veterinary Medicine.1992;14 (1-2): 87-98.

10. Laven RA and Peters AR. Bovine retained placenta: Aetiology, pathogenesis and economic loss. The Veterinary Record.1996; 139 (19): 465-471.

11. LeBlanc SJ. Postpartum uterine disease and dairy herd reproductive performance: A review. Veterinary Journal. 2008; 176 (1): $102-114$.

12. Lin JH, Wu LS, Wu YL, Lin CS and Yang NY. Aquapuncture therapy or repeat breeding in dairy cattle. The American Journal of Chinese Medicine. 2002; 30 (2-3): 397-404.

13. Lopez H, Satter LD and Wiltbank MC. Relationship between level of milk production and estrous behavior of lactating dairy cows. Animal Reproduction Science. 2004; 81(3-4): 209-223

14. Muxlow J. Importance of Estrus Detection on Dairy Farms: Evaluating Pedometers as a Possible Alternative to Visual Estrus Observation. 2005. Available at web site: https://www.afimilk.com/fr/node/114

15. Pérez-Marín CC and España F. Estrus expression and ovarian function in repeat breeder cows, monitored by ultrasonography and progesterone assay. Reproduction in Domestic Animals. 2007; 42 (5): 449-456.

16. Shamsuddin M, Bhuiyan MMU, Sikder TK, Sugulle AH, Chanda PK, Alam MGS and Galloway D. Constraints limiting the efficiency of artificial insemination of cattle in Bangladesh. Radioimmunoassay and related techniques to improve artificial insemination programs for cattle reared under tropical and sub-tropical conditions. Proceeding of final research coordination meeting, organized by the joint FAO/IAEA Division of nuclear techniques in Food and Agriculture and held in Uppsala, Sweden, 
Repeat breeding syndrome in crossbred dairy cows

10-14 May, 1999. IAEA-Tecdoc. 2001;1220:9-28.

17. Siddiqui MA, Shamsuddin M, Bhuiyan MM, Akbar MA and Kamaruddin KM. Effect of feeding and body condition score on multiple ovulation and embryo production in zebu cows. Reproduction in Domestic Animals. 2002; 37(1): 37-41.

18. Siddiqui MA, Das ZC, Bhattacharjee J, Rahman MM, Islam MM, Haque MA,
Parrish JJ, Shamsuddin M. Factors affecting the first service conception rate of cows in smallholder dairy farms in Bangladesh. Reproduction in Domestic Animals. 2013; 48(3): 500-505.

19. Zemjanis R. Repeat-Breeding or conception failure in cattle. In: Morrow DA edited Current Therapy in Theriogenology, WB Saunders, Philadelphia; 1980. pp. 205-213. 